\title{
Parent-Adolescent Discussion on Sexual and Reproductive Health Issues and Its Associated Factors Among Parents in Sawla Town, Gofa Zone, Ethiopia
}

Nigatu Teferi Malango

Gofa Zone Sowula Town Health Office

Tadele Yohannes Hegena ( $\square$ tadejoha@gmail.com )

WCU: Wachemo University https://orcid.org/0000-0003-3631-0484

Netsanet Abera Assefa

Hawassa University College of Medicine and Health Sciences

\section{Research}

Keywords: Parent-Adolescent discussion, SRH, Southern Ethiopia

Posted Date: December 8th, 2021

DOI: https://doi.org/10.21203/rs.3.rs-1124759/v1

License: @ (i) This work is licensed under a Creative Commons Attribution 4.0 International License. Read Full License 


\section{Abstract}

Background: Parent-adolescent discussion on sexual and reproductive health (SRH) issues leads to increased awareness on reproductive health matters and reduces risky behaviors among adolescents and also is the base to reduce depraved reproductive health outcomes. The aim of this study was to assess parent-adolescent discussion on SRH issues and its associated factors in Sawla town, Southern Ethiopia, 2020.

Methods: A community based cross sectional study was conducted among parents in Sawla town from March to April 2020. A simple random sampling technique was employed to select 697 study subjects. Data were entered in to Epi-data version 3.1 and exported to SPSS version 21 for analysis.

Variables with $p$-value less than 0.25 in bivariate analysis were entered into multiple logistic regression models to test for association with the dependent variable at $95 \%$ confidence level (Cl). P-value less than 0.05 and $95 \% \mathrm{Cl}$ for adjusted odds ratios (AOR) were used to declare the significance of the associations with the outcome variable.

Results: Of the total participants, $168(25.7 \%)$ respondents had reported discussion about at least two components of SRH issues in the last six months prior to the study. Multiple logistic regression model revealed that parents who attended primary education (AOR 3,95\% $\mathrm{Cl}: 1.10,7.70)$, secondary education (AOR 9, 95\% Cl: 3.87, 20.64) and diploma and above (AOR 22.33, 95\% Cl: 9.49, 32.56), monthly income of above 2000 Ethiopian Birr (AOR 2.40, 95\% Cl: 1.30, 4.55), good knowledge (AOR 2, 95\% Cl: 1.14, 3.50)and positive attitude (AOR 4, 95\% Cl: $1.57,10)$ towards SRH issues were statically significant with parent to adolescent discussion.

Conclusion: The occurrence of parent-adolescent SRH discussion is low in Sawla town. Educational status, average monthly income, knowledge and attitude on SRH issues were major factors affecting parentadolescent discussion on SRH issues. Continuous capacity building on SRH issues for parents to increase the level of parental knowledge and attitude about SRH issues and sustainable advocacy should be provided about the importance of parent to adolescent discussion. Moreover, it is important to support and scale up the adult learning program to decrease the level of illiteracy.

\section{Plain English Summary}

The health threats for adolescent's today are predominantly behavioral rather than biomedical and more of today's adolescents are involved in health behavior with potential for serious consequences. In most culture, parent and family members are influential source of knowledge, beliefs, attitudes, and values for children and youth. Open parent-adolescent discussion on sexual and reproductive health (SRH) issues often leads to increased awareness on reproductive health matters and reduces risky behaviors among adolescents and also is the base to reduce bad reproductive health outcomes. This study provides an overview of parent-adolescent discussion on SRH issues among parents in Sawla town in Southern Ethiopia. We found that only about one fourth $(25.7 \%)$ of the parents discuss on at least two components 
of SRH issues with their children in the last six months prior to the study. Educational status, average monthly income, knowledge and attitude on SRH issues were major factors for these disparities. Knowing the level of parent-adolescents discussion on SRH issues with their children and factors affecting the discussion may help concerned bodies to design Continuous capacity building and life skill training programs on $\mathrm{SRH}$ issues for parents and adolescents.

\section{Introduction}

Adolescence is a continuum of physical, cognitive, behavioral and psychosocial change that is characterized by increasing levels of individual autonomy, a growing sense of identity and self-esteem and progressive independence from adults (1). According to World Health Organization (WHO), it is one of the most rapid and formative phases of human development. These distinctive physical, cognitive, social, emotional and sexual development demands special attention in national development policies and programs (2).

Reproductive health implies that people are able to have a satisfying and safe sex life and that they have the ability to reproduce and the freedom to decide if, when and how often to do so (3). SRH regardless of age and sex concerns everyone for a large part of their lives. This issue starts to affect people's lives at adolescence, when they are familiar that they are starting to change from being children to adulthood (4).

Parent-adolescent discussion on $\mathrm{SRH}$ issues remains a challenging subject of discussion

in many traditional communities as the social environment in them still constrains exchange of information on such issues (5).

The results of adolescent sexual behavior are a huge burden both for the adolescent and society. The problem is not that adolescent are sexually active but rather that they have little preparation and guidance in developing responsible sexual behavior. Developmentally, adolescents reach physical maturity before they are cognitively able to appreciate the consequences of their behavior (6).

An adolescent's primary source of information regarding sexuality is his or her peer group, all of whom are experiencing and reinforcing the same behaviors. The family, the major fraternize of other behaviors, is not as powerful a force in shaping responsible sexual behavior because of parental discomfort with sex education and sexual discussions. This is the result of a social environment in which sex is frequently portrayed but rarely linked with responsible behavior or accurate, non-judgmental information (6).

Parents most often respond with their hopes that their children will grow into adulthood without unintended pregnancy or a sexually transmitted infection (STI). They sometimes follow this with the hope that their kids will never be a victim or perpetrator of intimate partner violence or other sexual abuse (7). 
The magnitude of parent-adolescent discussion about SRH issues is variable from country to country, being highest in United States of America (70.6\%), Mexico (83.1\%) and very low in countries like Myanmar $(6.8 \%)$ and India (13\%) in South and East Asia (8-11). A study conducted in Nigeria shows that $87.7 \%$ parents never discuss sexual matters with their adolescent girls (12), while another study in Alamata, Ethiopia shows that discussion was $14.7 \%$ with mothers, $3.9 \%$ with fathers, $15 \%$ with brothers or sisters, $23.4 \%$ with the same sex, $5.7 \%$ with the opposite sex and $15 \%$ discussed with health personnel (13).

Adolescents are exposed to various sexual and reproductive risks such as early sexual debut, unprotected sex, early pregnancy, school dropout and STI/HIV AIDS due to lack of communication with their parents. Worldwide, HIV/AIDS is the leading causes of disease burden for young people (those aged 10-24 years) (14). Half the newly acquired HIV infections occur in young people, with most of those affected living in developing countries $(14,15)$.

Different studies showed that parents lack of interest to discuss, feeling ashamed, culturally not acceptable, lack of communication skills, lack of awareness and belief that discussion will initiate sex as factors affecting parent-adolescent discussion on SRH matters ((16-18). Poor parental involvement in preparing adolescent people for SRH also put adolescents' victim of unwanted problems (19)

The government of Ethiopia developed Adolescent and Youth Reproductive Health (AYRH) Strategy in 2006, implemented from 2007 to 2015 and revised from 2016 to 2020. The strategy encouraged adolescents and youth to utilize available health services. Besides this various challenges ranging from limitations in the scope of the strategy, lack of coordination among implementing partners, low stakeholder and parent adolescent involvement, inadequate resources, and social and cultural barriers were faced in implementing the AYRH strategy (19).

Even though discussion on SRH issues is a public health concern among adolescents, it has not received due attention in Ethiopia. The Parent-adolescent discussion and associated factors were not well studied in Ethiopia especially in Southern part. The previous studies done were school based and focused discussion on SRH issues only from adolescents' point of view. Since this study was community based and from parents' point of view, it will play major role in filling research gaps on this issue. The study also helps for advocacy, guidance and program development about parent to adolescent discussion on SRH issues since there is no program provided in community and family level for adolescents to develop good decision-making skill and responsible sexual behavior. Therefore, this study aimed to investigate the parent to adolescent discussion of SRH issues and associated factors in Sawla Town, Southern Ethiopia.

\section{Materials And Methods}

\section{Study Area}

The study was conducted in Sawla Town, located in Southern nations and nationalities and People Regional State (SNNPR), Ethiopia. It is $310 \mathrm{~km}$ far from Hawassa, capital city of South Regional State in Ethiopia and $549 \mathrm{~km}$ away from Addis Ababa, the capital city of Ethiopia. Sawla has total population of 
46,957, of which $51 \%$ are females. According to Ethiopian Health and Demographic Survey (EDHS) 2019 , around $25.4 \%(11,927)$ adolescents were expected to live in the town. The town has 10 kebeles (smallest administrative unit) with 9,582 households; of these 3,903 households have adolescents. Sawla has one General Hospital, one public health center, two government clinics, nine private primary clinics, two private medium clinics, two pharmacies and seven drug stores which provide maternal and other health services to the population. Only one health center provides the adolescent and youth friendly services (20).

\section{Study design and period}

A community based cross-sectional study was conducted from March to April, 2020

\section{Study participants}

The source population was all parents living in Sawla town who had children between 10 and 19 years (adolescent) of age. Parents who were unable to communicate or severely ill at the time of data collection were excluded from the study.

\section{Sample size Determination and Sampling Procedure}

Sample size was calculated using double population proportion estimation formula in EPI-INFO version 7 based on key variables taken from previous studies. The assumptions are $95 \%$ confidence interval, $80 \%$ power of test and ratio of exposed to unexposed $=1: 1$. The calculated sample size was 634 . After adding a non-response rate of $10 \%$, the final sample size became 697 .

A simple random sampling method was employed to select the households. The number of households included in each kebele, the smallest administrative unit, is determined in proportion to the total number of households in each kebele. A computer generated random numbers were used to randomly select households from the lists of households who have adolescents (figure 1).

\section{Data collection and measurement}

Data was collected using pretested structured questionnaire, adapted from EDHS 2016 and other published literature $(21,22)$. The questionnaire consists of questions about socio-demographic factors, knowledge about SRH issues, attitude towards SRH issues and discussion between Parents and Adolescents concerning SRH issues. Parent-adolescent discussion on SRH issues was considered if they Discussed at least two SRH issues (physical and psychological changes during puberty, sexual intercourse, condom, STI/HIV/AIDS, unwanted pregnancy, contraception) with adolescents in the last 6 months (21, 23). Parents were considered as Knowledgeable on SRH if they Scored above the mean of sexual and reproductive health knowledge related questions $(21,24)$. Positive attitude about sexual and reproductive health issues was taken if they scored above the mean of SRH attitude related questions (21).

Face to face interviews were conducted by six experienced health professionals, supervised by public health officer from the town health office. Data collectors and supervisor were trained for two days through practical exercises. 


\section{Data quality and management}

Questionnaire was prepared in English language, translated to local language (Goffatho) and back translated to English by an expert for consistency. Questionnaire was pre-tested on $5 \%$ of the calculated sample size among parents from Galma Town which is not included in the actual study to ensure clarity of the questionnaire and then the necessary modifications and correction was made to standardize and ensure its validity. Adjustments in the sequence and wording were made based on the results of the pretest. Questionnaire was checked for completeness on a daily basis. Incorrectly filled or missed questionnaire were sent back to respective data collector for correction. Principal investigator would recheck the completed questionnaires.

\section{Data processing and analysis}

The collected data was coded and entered in to Epi-Data Version 3.1 (25) and analyzed using SPSS Version 21 software (26). Descriptive analysis such as proportions, measure of central tendency and dispersion were computed for relevant variables. Model fitness was tested using Hosmer and Lemeshow test (>0.05).All variables with $p$-value less than 0.25 in bivariate analysis were entered into multiple logistic regression model to test for association with the dependent variable at $95 \%$ confidence level $(\mathrm{Cl})$. P-value less than 0.05 and $95 \% \mathrm{Cl}$ for adjusted odds ratios (AOR) were used to declare the significance of the associations with the outcome variable.

\section{Results}

\section{Socio - demographic characteristics of respondents}

The response rate was $94 \%$ ( 653 of 697 parents participated). The mean age of respondents was 42 years (standard deviation (SD) 6.60). Most of the respondents (521, 79.80\%) were Christians. and ethnically Gofa $(518,79.3 \%)$. One hundred fifty-three $(23.4 \%)$ of the respondents had no formal education while majority, $(227,34.8 \%)$ were civil servants. One hundred forty-five $(22.2 \%)$ had monthly income of 1000 2000 Ethiopian Birr. Majority of the respondents were married $(581,89 \%)$ and were either father $(320,49 \%)$, mother $(322,49.3 \%)$ or guardian $(11,1.7 \%)$ (Table1). 
Table 1

Socio demographic characteristics of participants of parent-adolescent discussion about SRH issues study in Sawla town, Southern Ethiopia 2020 $(\mathrm{n}=653)$

\begin{tabular}{|c|c|c|c|}
\hline Variable & Category & Frequency & $\%$ \\
\hline \multirow[t]{3}{*}{ Age } & $<35$ & 62 & 9.5 \\
\hline & $35-45$ & 405 & 62.0 \\
\hline & $>45$ & 186 & 28.5 \\
\hline \multirow[t]{2}{*}{ Sex } & Male & 322 & 49.3 \\
\hline & Female & 331 & 50.7 \\
\hline \multirow[t]{2}{*}{ Religion } & Christian & 521 & 79.8 \\
\hline & Muslim & 132 & 20.2 \\
\hline \multirow[t]{2}{*}{ Ethnic group } & Gofa & 518 & 79.3 \\
\hline & Others* & 135 & 20.7 \\
\hline \multirow[t]{4}{*}{ Educational level } & No formal education & 153 & 23.4 \\
\hline & Primary School & 99 & 15.2 \\
\hline & Secondary school & 129 & 19.8 \\
\hline & Diploma and above & 272 & 41.7 \\
\hline \multirow[t]{4}{*}{ Occupation } & Daily labors & 119 & 18.2 \\
\hline & Civil servants & 227 & 34.8 \\
\hline & Private sector employee & 108 & 16.5 \\
\hline & Merchant & 199 & 30.5 \\
\hline \multirow[t]{3}{*}{ Monthly income } & $<1000$ & 25 & 3.8 \\
\hline & $1000-2000$ & 145 & 22.2 \\
\hline & $>2000$ & 483 & 74.0 \\
\hline \multirow[t]{4}{*}{ Marital status } & Single & 10 & 1.5 \\
\hline & Married & 581 & 89.0 \\
\hline & Divorced & 44 & 6.7 \\
\hline & Widowed & 18 & 2.8 \\
\hline Relation with adolescent & Father & 320 & 49.0 \\
\hline
\end{tabular}




\begin{tabular}{|lllll|}
\hline Variable & Category & Frequency & $\%$ \\
\hline & Mother & 322 & 49.3 \\
\cline { 3 - 5 } & Guardian & 11 & 1.7 \\
\hline *Gamo, Wolayta, Oyda & & & \\
\hline
\end{tabular}

\section{Knowledge towards SRH issues}

Concerning participants' knowledge of SRH issues about 72\% (473) were considered to have good knowledge. Of the total 653 respondents, almost all knew about at least one contraceptive method 641 $98.2 \%)$. When asked separately, majority knew about injectable (96\%), condom (95.4\%), pills (91\%) and natural safe period (70.9\%). Almost all (98\%) participants knew at least one STI including HIV/AIDS. Specifically, majority knew about HIV/AIDS (98.3\%) and Syphilis (89.9\%) followed by Cancroid (66.5\%). Almost all respondents knew at least one physical and behavioral change during puberty $649(99.4 \%)$. They mentioned breast development, onset of menstruation in females, change in voice in both sexes, refusal of parent command, feeling angry for minor reasons and interest towards opposite sex $99.1 \%, 98.3 \%, 96.6 \%$, $77.3 \%, 73.2 \%$ and $71.7 \%$, respectively (Table 2 ) 
Table 2

Knowledge of parents on parent-adolescent discussion about SRH issues in Sawla town, Southern Ethiopia $2020(n=653)$

\begin{tabular}{|c|c|c|c|}
\hline Variables & Category & Frequency & $\%$ \\
\hline \multirow[t]{2}{*}{ Knowledge about SRH issues } & Good & 473 & 72.4 \\
\hline & Poor & 180 & 27.6 \\
\hline \multirow[t]{2}{*}{ Ever heard of SRH } & Yes & 629 & 96.3 \\
\hline & No & 24 & 3.7 \\
\hline \multirow[t]{2}{*}{ Knew at least one contraceptive method } & Yes & 641 & 98.2 \\
\hline & No & 12 & 1.8 \\
\hline \multirow[t]{6}{*}{ Type of contraceptive* } & Pill & 594 & 91.0 \\
\hline & Condom & 623 & 95.4 \\
\hline & Injectable & 627 & 96.0 \\
\hline & Implants & 284 & 43.5 \\
\hline & IUCD & 256 & 39.2 \\
\hline & Natural safe period & 463 & 70.9 \\
\hline \multirow[t]{2}{*}{ Knew at least one STI including HIV-AIDS } & Yes & 640 & 98.0 \\
\hline & No & 13 & 2.0 \\
\hline \multirow[t]{6}{*}{ Type of STI/HIV-AIDS* } & Chancroid & 434 & 66.5 \\
\hline & Syphilis & 587 & 89.9 \\
\hline & Gonorrhea & 310 & 47.5 \\
\hline & $\begin{array}{l}\text { Lympho granuloma } \\
\text { venerum }\end{array}$ & 154 & 23.6 \\
\hline & HIV/AIDS & 642 & 98.3 \\
\hline & Herpes simplex & 86 & 13.2 \\
\hline \multirow{2}{*}{$\begin{array}{l}\text { Knew at least physical and behavioral change } \\
\text { during puberty }\end{array}$} & Yes & 649 & 99.4 \\
\hline & No & 4 & 0.6 \\
\hline \multirow[t]{2}{*}{$\begin{array}{l}\text { Type of physical and behavioral changes during } \\
\text { puberty* }\end{array}$} & $\begin{array}{l}\text { Breast development in } \\
\text { female }\end{array}$ & 647 & 99.1 \\
\hline & $\begin{array}{l}\text { On set of menstruation in } \\
\text { females }\end{array}$ & 642 & 98.3 \\
\hline
\end{tabular}

*Multiple choices was possible 


\begin{tabular}{|lllr|}
\hline Variables & Category & Frequency & \% \\
\hline & Change in voice in both sex & 631 & 96.6 \\
\cline { 2 - 4 } & Refuse parent command & 505 & 77.3 \\
\hline & $\begin{array}{l}\text { Interest towards opposite } \\
\text { sex }\end{array}$ & 468 & 71.7 \\
\hline & $\begin{array}{l}\text { Feel angry for minor } \\
\text { reasons }\end{array}$ & 478 & 73.2 \\
\hline *Multiple choices was possible & & & \\
\hline
\end{tabular}

\section{Attitude about SRH issues}

Overall, 582 (89.1\%) participants had positive attitude towards SRH issues. Majority of respondents $447(68.50 \%)$ strongly disagree accepting premarital sex, while $5(0.80 \%)$ had no problem with having premarital sex. Of all participant parents who responded about girl's virginity, 357 (54.70\%) agreed that girls have to remain virgin until they get married. More than half $(362,55.44 \%)$ of parents agree that boys have to remain virgin until they are married. Of the total 653 respondents, $400(61.3 \%)$ believed that parent to adolescent discussion on SRH issues can delay first sexual intercourse. Four hundred sixty-four $(71.10 \%)$ of parents believed that if unmarried couples want to have sexual intercourse before marriage they must use condom. Of all, $442(67.70 \%)$ believed that HIV/AIDs and other STIs can be prevented by using condom during sexual intercourse. Three hundred thirty-two (50.80\%) reported that their culture forbids parent to adolescent discussion about SRH issues.

\section{Discussion on SRH issues}

The study showed that 485 (74.27\%) of the total participants did not have any discussion on SRH issues (figure 2).

Topics discussed between parents and adolescents about SRH issues were puberty (54, 8.3\%), sexual intercourse $(156,23.9 \%)$, contraception $(46,7.0 \%)$, condom use $(24,3.7 \%)$, STI $(138,21.1 \%)$ and unintended pregnancy $(120,18.4 \%)$ (Table3). 
Table 3

SRH topics discussed between parents and adolescents in Sawla town, Southern Ethiopia $2020(n=653)$

\begin{tabular}{|llll|}
\hline Variable & Category & Frequency & $\%$ \\
\hline Puberty discussion* & Yes & 54 & 8.30 \\
\cline { 2 - 4 } & No & 599 & 91.70 \\
\hline Sexual intercourse* & Yes & 156 & 23.90 \\
\cline { 2 - 4 } & No & 497 & 76.10 \\
\hline Contraception* & Yes & 46 & 7.00 \\
\cline { 2 - 4 } Condom* & No & 607 & 93.00 \\
\hline STI* & Yes & 24 & 3.70 \\
\cline { 2 - 4 } & No & 629 & 96.30 \\
\hline Unintended pregnancy* & Yes & 138 & 21.10 \\
\cline { 2 - 4 } & No & 515 & 8.90 \\
\hline No & 533 & 81.60 \\
\hline *Multiple choices was possible & & \\
\hline
\end{tabular}

Factors associated with parent to adolescent discussion on $\mathrm{SRH}$ issues

On bivariate logistic regression religion, educational status, occupation, monthly income, marital status, knowledge and attitude about SRH issues were found to be significantly associated with discussion on $\mathrm{SRH}$ issues (Table 4). 
Table 4

Bivariate analysis of parent to adolescent discussion on SRH issues in Sawla town, Southern Ethiopia, 2020

\begin{tabular}{|c|c|c|c|c|c|}
\hline \multirow[t]{2}{*}{ Variables } & \multirow[t]{2}{*}{ Category } & \multicolumn{2}{|c|}{$\begin{array}{l}\text { Parent-Adolescent SRH } \\
\text { discussion }\end{array}$} & \multirow{2}{*}{$\begin{array}{l}\text { Crude Odds ratio } \\
\text { (COR) } \\
(95 \% \mathrm{Cl})\end{array}$} & \multirow[t]{2}{*}{$\begin{array}{l}\text { p- } \\
\text { value }\end{array}$} \\
\hline & & Yes (\%) & No $(\%)$ & & \\
\hline \multirow[t]{2}{*}{ Religion } & Christian & $137(26.3)$ & $384(73.7)$ & & \multirow[b]{2}{*}{.059} \\
\hline & Muslim & $31(23.5)$ & $101(76.5)$ & $0.88(0.56,1.38)$ & \\
\hline \multirow[t]{4}{*}{ Marital status } & Married & $152(26.2)$ & $429(73.8)$ & 1 & \\
\hline & Divorced & $6(13.6)$ & $38(86.4)$ & $0.39(0.19,0.78)$ & .001 \\
\hline & Single & $2(20,0)$ & $8(80.0)$ & $0.49(0.24,0.99)$ & .002 \\
\hline & Widowed & $8(44.4)$ & $10(55.6)$ & $1(0.38,1.62)$ & \\
\hline \multirow[t]{4}{*}{ Educational level } & $\begin{array}{l}\text { No formal } \\
\text { education }\end{array}$ & $7(4.6)$ & $146(95.4)$ & 1 & \\
\hline & Primary school & $12(12.1)$ & $87(87.9)$ & $3.26(1.24,8.53)$ & .002 \\
\hline & Secondary school & $51(39.5)$ & $78(60.5)$ & $11.373(5.00,25.86)$ & $<.001$ \\
\hline & $\begin{array}{l}\text { Diploma and } \\
\text { above }\end{array}$ & $98(36.0)$ & $174(64.0)$ & $29(17.25,52.96)$ & .043 \\
\hline \multirow[t]{4}{*}{ Occupation } & Daily laborer & $5(4.2)$ & 114(95.8) & 1 & \\
\hline & Civil Servant & $76(33.5)$ & $151(66.5)$ & $22.30(8.50,58.40)$ & .001 \\
\hline & $\begin{array}{l}\text { Private sector } \\
\text { employee }\end{array}$ & $56(51.9)$ & $52(48.1)$ & $5.16(2.00,13.33)$ & $<0.001$ \\
\hline & Merchant & $31(15.6)$ & $168(84.4)$ & $3.74(1.40,9.97)$ & .002 \\
\hline \multirow[t]{3}{*}{ Monthly income } & $<1000$ & $6(24.0)$ & 19(76.0) & 1 & \\
\hline & $1000-2000$ & $44(30.3)$ & $101(69.7)$ & $2.07(1.16,3.69)$ & .023 \\
\hline & $>2000$ & 118(24.4) & $365(75.6)$ & $7.35(4.29,12.62)$ & .003 \\
\hline \multirow{2}{*}{$\begin{array}{l}\text { Knowledge } \\
\text { about SRH }\end{array}$} & Poor & $20(11.1)$ & 160(88.9) & 1 & \\
\hline & Good & $148(31.3)$ & $325(68.7)$ & $3.64(2.20,6.03)$ & .002 \\
\hline \multirow{2}{*}{$\begin{array}{l}\text { Attitude about } \\
\text { SRH }\end{array}$} & Negative & $6(8.5)$ & $65(91.5)$ & 1 & \\
\hline & Positive & 162(27.8) & $420(72.2)$ & $4.18(1.78,9.83)$ & .015 \\
\hline
\end{tabular}


Multiple logistic regression model revealed that parents who have attended primary education were three times more likely to discuss SRH issues compared to those with no formal education (AOR $3,95 \% \mathrm{Cl}$ : 1.10,7.70). Parents who have attended secondary education were nine times more likely to discuss SRH issues compared to those with no formal education (AOR 9, 95\% Cl: 3.87, 20.64). The odds of discussion on $\mathrm{SRH}$ issues among adolescents and their parents was 22.3 times more likely among parents who attended higher education (diploma and above) (AOR 22.33, 95\% Cl: 9.49,32.56).

Parents who reported a monthly income of above 2000 Ethiopian Birr were 2.4 times more likely to discuss $\mathrm{SRH}$ issues with their adolescents (AOR $2.40,95 \% \mathrm{Cl}: 1.30,4.55)$ compared to parents with a monthly income less than 1000 Birr.

Parents who had good SRH knowledge were two-fold more likely to discuss SRH issues with their adolescents (AOR 2, 95\% Cl: 1.14, 3.50) than their counterparts. The odds of discussing SRH issues with their adolescents were 4 times higher among parents who had positive attitude than their counterparts (AOR 4, 95\% Cl: 1.57, 10) (Table 5). 
Table 5

Multi-variable analysis of factors related with parent to adolescent discussion on SRH issues in Sawla town, Southern Ethiopia, 2020

\begin{tabular}{|c|c|c|c|c|c|c|}
\hline \multirow[t]{2}{*}{ Variables } & \multirow[t]{2}{*}{ Category } & \multicolumn{2}{|c|}{$\begin{array}{l}\text { Parent-Adolescent } \\
\text { SRH discussion }\end{array}$} & \multirow{2}{*}{$\begin{array}{l}\text { COR } \\
(95 \% \mathrm{Cl})\end{array}$} & \multirow{2}{*}{$\begin{array}{l}\text { AOR } \\
(95 \% \mathrm{Cl})\end{array}$} & \multirow[t]{2}{*}{$\begin{array}{l}\mathrm{p}- \\
\text { value }\end{array}$} \\
\hline & & Yes (\%) & No (\%) & & & \\
\hline \multirow[t]{4}{*}{$\begin{array}{l}\text { Educational } \\
\text { level }\end{array}$} & $\begin{array}{l}\text { No formal } \\
\text { education }\end{array}$ & $7(4.6)$ & $146(95.4)$ & 1 & 1 & \\
\hline & $\begin{array}{l}\text { Primary } \\
\text { school }\end{array}$ & $12(12.1)$ & $87(87.9)$ & $3.26(1.24,8.53)$ & $3(1.10,7.70)$ & .001 \\
\hline & $\begin{array}{l}\text { Secondary } \\
\text { school }\end{array}$ & $51(39.5)$ & $78(60.5)$ & $11.373(5,25.86)$ & $9(3.87,20.64)$ & .003 \\
\hline & $\begin{array}{l}\text { Diploma } \\
\text { and above }\end{array}$ & $98(36.0)$ & $174(64.0)$ & $29(17.25,52.96)$ & $22.33(9.49,32.56)$ & .002 \\
\hline \multirow{3}{*}{$\begin{array}{l}\text { Monthly } \\
\text { income }\end{array}$} & $<1000$ & $6(24.0)$ & 19(76.0) & 1 & 1 & \\
\hline & $\begin{array}{l}1000- \\
2000\end{array}$ & $44(30.3)$ & $101(69.7)$ & $2.07(1.16,3.69)$ & $1.3(0.70,2.50)$ & \\
\hline & $>2000$ & 118(24.4) & $365(75.6)$ & $7.35(4.29,12.62)$ & $2.4(1.30,4.55)$ & .001 \\
\hline \multirow{2}{*}{$\begin{array}{l}\text { Knowledge } \\
\text { about SRH }\end{array}$} & Poor & $20(11.1)$ & $160(88.9)$ & 1 & 1 & \\
\hline & Good & $148(31.3)$ & $325(68.7)$ & $3.64(2.20,6.03)$ & $2(1.14,3.50)$ & $\leq .001$ \\
\hline \multirow{2}{*}{$\begin{array}{l}\text { Attitude } \\
\text { about SRH }\end{array}$} & Negative & $6(8.5)$ & $65(91.5)$ & 1 & 1 & \\
\hline & Positive & 162(27.8) & $420(72.2)$ & $4.18(1.78,9.83)$ & $4(1.57,10)$ & .001 \\
\hline
\end{tabular}

\section{Discussion}

This study was conducted to assess parent to adolescent discussion about SRH issues from parents' perspective including knowledge, reasons and associated factors.

In this study $25.7 \%$ (95\% Cl: $22.48 \%, 29.19 \%)$ parents reported that they had discussion on two or more topics in the last six months prior to the study about SRH issues with their adolescent children. This finding is similar to findings from other different regions of Ethiopia like Awabel Woreda in East Gojjam/Western Ethiopia (25.3\%), Harar (28.7\%) and Benishangul Gumuuz (28.9\%). Similar findings were reported from China(27) which shows that the discussion rarely occurs despite accepting its importance. The results of this study are relatively higher than studies from Zeway, Ethiopia (20\%) (28) and Lesotho (20\%) (29). This difference could have been due to the time gap as improvement in accessing SRH information may have occurred. This result is also lower than the findings in Mekele (57.6\%) and Alamata (68.2\%). The difference might be due to difference in measurement tools as study in Mekele considered discussion on one topic enough as compared to this study where at least two topics were used as cutoff. Similarly, different results 
from the study in Alamata may be due to the fact that, they considered discussions between sisters, brothers and health personals as parental discussion $(13,30)$. When compared to results from studies in other continents the results were much lower. For example Mexico reported 83.1\% parents have spoken to their children about SRH issues (11). A study from New York, Alabama reported about the proportion to be $70.6 \%$ (9). This might be due to difference in educational level of parents, knowledge, skill of communication and accessing sexual and reproductive health information which is better in Mexico and New York, Alabama compared to Ethiopia.

In this study discussion about puberty was $8.3 \%$, which is similar to previous study done in Ziway (10.6\%) (28). However, this result was much lower than in the result reported from Yirgalem, southern Ethiopia (39.7\%). This difference may be a result of difference in measuring tool as they considered one topic enough to constitute parental discussion. In addition time period was not restricted, which may have resulted in increased proportion (31). The discussion about sexual intercourse (23.9\%) was similar to study done in Debremarkos (27.6\%) but much lower than the studies done in Yirgalem (33.5\%), Bullen woreda of Benishangul Gumuuz (42.2\%) and Harar (50.02\%). This may be due to different in measurement criteria. In Bullen, discussion with teachers, friends, sisters and brothers was considered as being part of having parental discussion $(21,23,31,32)$.

Only $7 \%$ participants in this study reported discussion on contraception. This is lower than reported by other studies done in different parts of Ethiopia, including in Debremarkos (25.9\%), Harar (26.39\%), Yirgalem (36.1\%) and Bullen woreda of Benishangul Gumuuz (41.3\%). The difference may similar to as reported above, being difference in measurement criteria $(21,23,31,32)$. Only $3.7 \%$ of the participants from this study discussed condom use and the result is far lower than other studies done in Ethiopia (21, $31,32)$.

One fifth (21.1\%) participants of this study discussed about STI and HIV/AIDS. This is lower than the study in Bullen woreda of Benishangul Gumuuz, Ethiopia (78.6\%). This may be due to difference in study population and that they considered discussions between teachers, friends, sisters and brothers as parental discussion (32). Eighteen percent of the respondents discussed about unintended pregnancy which is similar to the study from Ziway (20.7\%) but much lower than other studies in Debremarkos (28.5\%), Yirgalem (36.1\%), Harar (42.59\%) and in Bullen Benishangul Gumuuz (54.1\%) This may be due to difference in measurement tools and study population $(21,23,28,31,32)$.

Parents also indicated various reasons why they do not discuss sexual and reproductive health issues with their adolescents. Among the major reasons, cultural norms (54.2\%) was mentioned which is in line with the study done in Ziway (54\%) but greater than other studies done in Yirgalem, Harar and Bullen woreda of Benishangul Gumuuz $(21,23,28,31,32)$. This shows existence of extensive cultural taboos throughout the country. Fear of discussion (41.5\%) was also mentioned as one of the major reasons this is in line with many other researches $(18,23,31,33)$. This may be due to the taboo nature of discussion about SRH issues in many Ethiopian settings. 
Thirty-six percent of the respondents do not discuss due to lack of communication skills. This result is consistent with many studies done in different parts of Ethiopia and from abroad $(18,23,31,33,34)$ indicating a gap in communication skills among parents. Belief that discussion would initiate sex (34\%) was also mentioned as a reason, which is similar to the study done in Debremarkos (33.1\%) and Harar (33.8\%) where parents perceive that discussing sexual matters with their adolescents might encourage the children to engage in premarital sex $(21,23)$. Some of the participants also mentioned lack of knowledge $(20.8 \%)$ as a reason for no discussion. This result is similar to the study done in Wollega and Benishangul Gumuuz $(32,33)$. This may be due to parents' perspective that the adolescents know more than them.

Majority of the participants had good knowledge about SRH issues (72.4\%) (95\% Cl: $68.91 \%, 75.76 \%)$. This is greater than the studies done in different parts of Ethiopia like, Harar (67.38\%) and Debremarkos $(57.3 \%)$. This difference may be due to time gap between the studies which may have resulted in improvements in available resources $(21,23)$.

The result of multiple logistic regression models revealed that parents who had no formal education were less likely to discuss about SRH issues when compared to those parents who had primary education (AOR $3,95 \% \mathrm{Cl}: 1.1,7.7$ ), secondary education (AOR 9, 95\% Cl: 3.87, 20.64) and diploma and above (AOR 22.33, $95 \% \mathrm{Cl}: 9.49,32.56)$.This result is consistent with different previous studies $(23,33-36)$. This may be due to educated parents have better information about SRH issues and communication skills, so that they are more likely to discuss than those with no formal education. Knowledge leads to the development of desirable attitude and builds confidence in parents to shoulder the matter.

Parents who reported a monthly income of above 2000 Ethiopian Birr were 2.4 times more likely to discuss $\mathrm{SRH}$ issues with their adolescents (AOR 2.4, 95\% Cl:1.3, 4.55) compared to parents with a monthly income of less than 1000 Birr. This is similar to the study done in Harar (23). Parents who had good SRH knowledge had a two fold increase in the odds of discussing SRH issues with their adolescents (AOR 2, $95 \% \mathrm{Cl}: 1.14,3.5)$ than their counterparts. This result was consistent with previous findings $(23,33,34,36)$. This may be due to respondents who had good knowledge were eager to discuss and their knowledge may initiate discussion and they may have interest to share their knowledge. The odds of discussion on SRH issues were 4 times higher among parents who had positive attitude than their counterparts (AOR 4, 95\% $\mathrm{Cl}: 1.57,10)$.This result was also consistent with previous findings $(23,33,34,36)$. This may be due to their perceived importance of discussion for their adolescents.

\section{Limitation of the study}

The study was based on self-reporting and responses might be affected by social desirability bias because of the sensitive nature and cultural barriers for reporting. Since the study design was cross sectional, cause and effect relationship could not be established.

\section{Conclusion}


Different evidences suggest that parent to adolescent discussion on reproductive health issues is the basis for safe and healthy transition to adulthood. However, in this study even if parents had good knowledge and positive attitude, the proportion of discussion about sexual and reproductive health is low. This is bounded by different cultural taboos, fear of discussion and lacks of communication skill and belief that talking about sex will initiates sex. Parents who attended primary education had better chance of discussing on SRH issues with adolescents. Those with higher monthly income had discussed on SRH with adolescents. Similarly, those with good knowledge and positive attitude also had discussed about $\mathrm{SRH}$ with their adolescents than their counterparts. We recommend provision of continuous capacity building on SRH issues for parents to increase the level of parental knowledge and attitude about SRH issues and sustainable advocacy should be provided about the importance of parent to adolescent discussion. Moreover, it is important to support and scale up the adult learning program to decrease the level of illiteracy. Finally, research is needed to fully understand the issues relevant to social meanings and beliefs that were major reason for low discussion between parent and adolescent.

\section{Abbreviations}

AIDS, Acquired Immune deficiency Syndrome; AOR, Adjusted Odds Ratio; $\mathrm{Cl}$, Confidence Interval; COR, Crude Odds Ratio; EDHS, Ethiopian Demographic and Health Survey; HIV, Human Immune Virus; $\mathrm{HH}$, House Holds; IUCD, Intra Uterine Contraceptive Device; KMs, Kilometers; SD, Standard Deviation; RH, Reproductive Health; SPSS, Statistical Package for Social Science; SRH, Sexual and Reproductive Health; STD, Sexually Transmitted Disease; STI, Sexually Transmitted Infection; UNFPA, United Nation Population Fund; WHO, World Health Organization

\section{Declarations}

\section{Ethical Approval}

Ethical clearance was obtained from Institutional Review Board (IRB) of Hawassa University College of Medicine and Health Sciences and the official letter was obtained from Sawla Town health office. Written informed consent was obtained from each participant after explaining the nature, purpose and procedure of the study. A thumbprint or signature was obtained on the consent form.

\section{Authors' contributions}

Nigatu Teferi conceived the research idea, conducted the data collection, data analysis and data interpretation, and wrote and reviewed the paper. NetsanetAbera and TadeleYohannes approved the proposal, participated in data analysis and revised subsequent draft of the paper. All authors read and approved the final paper.

\section{Consent for Publication}


Not applicable.

\section{Competing of Interest}

The authors declare that they have no competing interests.

\section{Data Availability}

The datasets during the current study are available from the corresponding author on reasonable request.

\section{Funding}

Not applicable.

We would like to thank Hawassa University College of Medicine and Health Sciences for providing us the opportunity to carry out this study. Our gratitude also goes to Sawla town health office, study participants, supervisors and data collectors for their cooperation during the entire process of data collection.

\section{References}

1. UNFPA. Adolescent Sexual and Reproductive Health for Humanitarian Settings. 2009:5-6.

2. WHO. Adolescent health and development program manual of operations. 2017;:;(20-1).

3. McIntosh CA, Finkle JL. The Cairo conference on population and development: A new paradigm? Population and development review1995:223-60.

4. Nosworthy D. Resource pack-sexual and reproductive health. action for the rights of children. 2018.

5. Kumi-Kyereme A A-AK, Biddlecom A, Tanle A.,. Influence of social connectedness, communication and monitoring on adolescent sexual activity in Ghana. African journal of reproductive health, 2017.

6. Grant LM DE. Adolescent sexuality. Pediatric clinician North America. Boston University2011;35(6):1271-89.

7. MM. McGee. M. Talking With Kids Openly and Honestly About Sexuality.,This is Google's cache of http://www.advocatesforyouth.org/sexeducation.htm. Appeared on September 222011.

8. Jejeebhoy SJ, Zavier A, Santhya K, Singh SK, Acharya R, Gogoi A, et al. Promoting parent-child interaction and communication for healthy development of adolescents: Lessons from a pilot project in rural Bihar. 2014.

9. Miller KS LM, Whitaker DJ, Xu X.. Patterns of Condom Use Among Adolescents : The Impact of Mother-Adolescent Communication.. 2012;88(10):3-6.

10. Nu. Y ZK, et al:. Do parents and adolescents talk about reproductive health ? Myanmar adolescents perspective. South East Asia. J Public Heal2011(5):5-40.

11. Robin L PD, Dittus P, Ph D, Whitaker D, Ph D, et al. Behavioral Interventions to Reduce Incidence of HIV, STD, and Pregnancy Among Adolescents :. A Decade in Review2014(3):3-26. 
12. LA b. Parent view point on reproductive health and contraceptive practice among sexual active adolescent in the Harcourt Nigeria.. Journal of advancing nursing 2012;27:261-6.

13. Abebe N MG. Assessment of Parent Adolescent Communication on Sexual and Reproductive Health Issues and Associated Factors in Alamata. 2013:83-92.

14. WHO. The sexual and reproductive health of young adolescents in developing countries: reviewing the evidence, identifying research gaps, and moving the agenda: report of a WHO technical consultation, Geneva, 4-5 November 2010: Geneva: World Health Organization2011.

15. Patton GCaRV. Patton, G.C. and R. Viner, Pubertal transitions in health.. Lancet,2017;369.

16. Bo Wang BS, Lynette Deveaux, Xiaoming Li, and a.S.L. Veronica Koci,. The impact of parent involvement in an effective adolescent risk reduction intervention on sexual risk communication and adolescent outcomes.,. AIDS Education and Prevention2014;26(6):500-20.

17. Dadi AF TF. Risky sexual behavior and associated factors among grade 9-12 students in Humera secondary school, western zone of Tigray, NW Ethiopia,. 2014;2(5):410-6.

18. Sagaro MFSLG, Meskele M.. Factors associated with adolescent - parent communication regarding reproductive health issues, among high school and preparatory students in Boditi town, Southern Ethiopia : a cross-sectional study.. Patient Intell2016:57-70.

19. MOH. Adolescent and Youth Reproductive Health. 2018:3-39.

20. EDHS. Ethiopia Demographic and Health Survey. WEB PAGE. [DATA SHEET]. 2019(2019):13-4.

21. kasiye Shiferaw FaG. Assessment of adolescents ' communication on sexual and reproductive health matters with parents and associated factors among secondary and preparatory schools ' students in Debremarkos.. Reprod Health 2014;11(2):1-10.

22. Motuma A ST, Egata G, Kenay A. Utilization of youth friendly services and associated factors among youth in Harar town, east Ethiopia : a mixed method study.. BMC Health Serv Res [Internet]2016:1-10.

23. Yadeta TA BH, Tura AK.. Factors Affecting Parent-Adolescent Discussion on Reproductive Health Issues in Harar, Eastern Ethiopia : A Cross-Sectional Study. Environ public Health2014:3-5.

24. Zewdu S. Assessment of Adolescent Parent Communication Concerning Sexual and Reproductive Health Issues among Ayer Tena Preparatory School Students medline2017;2:6-16.

25. EpiData Http://www.epidata.dk/funding.htm.

26. SPSS 21:00 for windows. www.SPSS.com.

27. Wang XLBea. Sexual attitudes, pattern of communication, and sexual behavior amongunmarried outof- school youth in China. BMC Public Heal2007;7(189):3-10.

28. Taffa.N. HR. Do parent and young people communicated on sexual matters? The situation of family life education in Ziway town of Ethiopia. Ethiopian journal of health development 2014;13(3):205-6.

29. AJ D. Parent attitude to adolescent sexual behavior in Lesotho. Afr J Reprod Health2013;17(2):25-8.

30. Yowhanes Z BH, Hailu D. Assessment of Parent-Adolescent Communication about Sexual and Reproductive Health among High School Students in Mekelle Town, Northern Ethiopia. pubmed2016;2:2-15. 
31. Tsegay. ZYaB. Barriers of Parent-Adolescent Communication on Sexual and Reproductive Health Issues among Secondary and Preparatory School Students in Yirgalem Town South Ethiopia. Fam Med Med Sci Res2015;4:4-11.

32. G/yesus. D. Assessing communication on sexual and reproductive health issues among high school students with their parents, in Bullen woreda benishangul.. Addis Ababa Univ 2010:20-46.

33. Tesso DW FM, Enquselassie F. Parent-young people communication about sexual and reproductive health in E / Wollega zone, West Ethiopia :. Reprod Health [Internet]2012;9(1):3-10.

34. Fikire. M. Assessment of parent-adolescent communication on sexual and reproductive health.. 2009:30-53.

35. Barbara.H KB. Parent-Child Communication Resources for Asian/Pacific Islander, Native American, and Latino Families.,. Advocates for youth WashingtonDC2018:200.

36. GA. KSFa. Assessment of adolescents ' communication on sexual and reproductive health matters with parents and associated factors among secondary and preparatory schools ' students in Debremarkos. 2014:1-10.

\section{Figures}




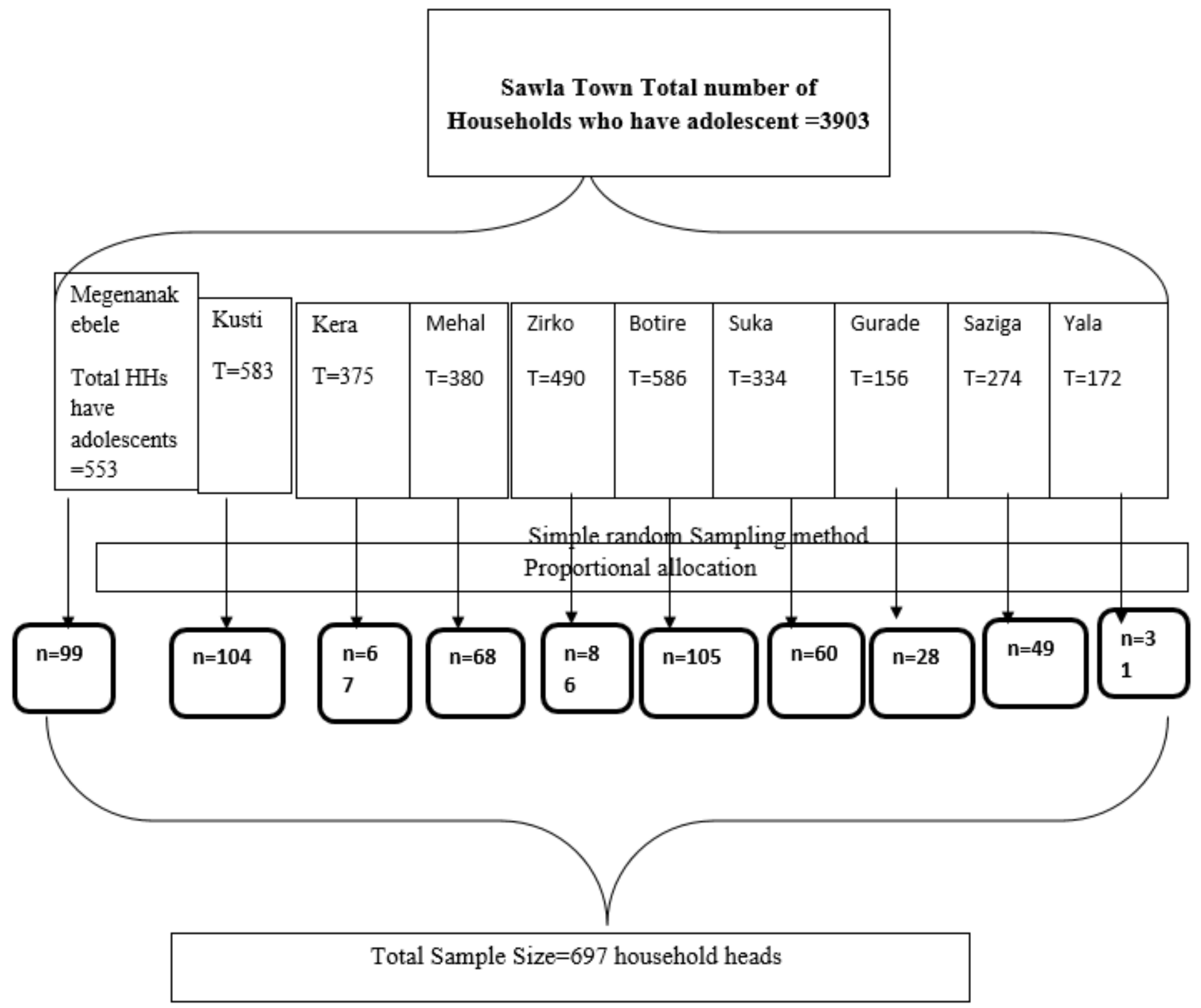

Figure 1

Schematic representation of the sampling procedure of parent-adolescent discussion and associated factors on SRH issues among parents in Sawla town, Southern Ethiopia, 2020 


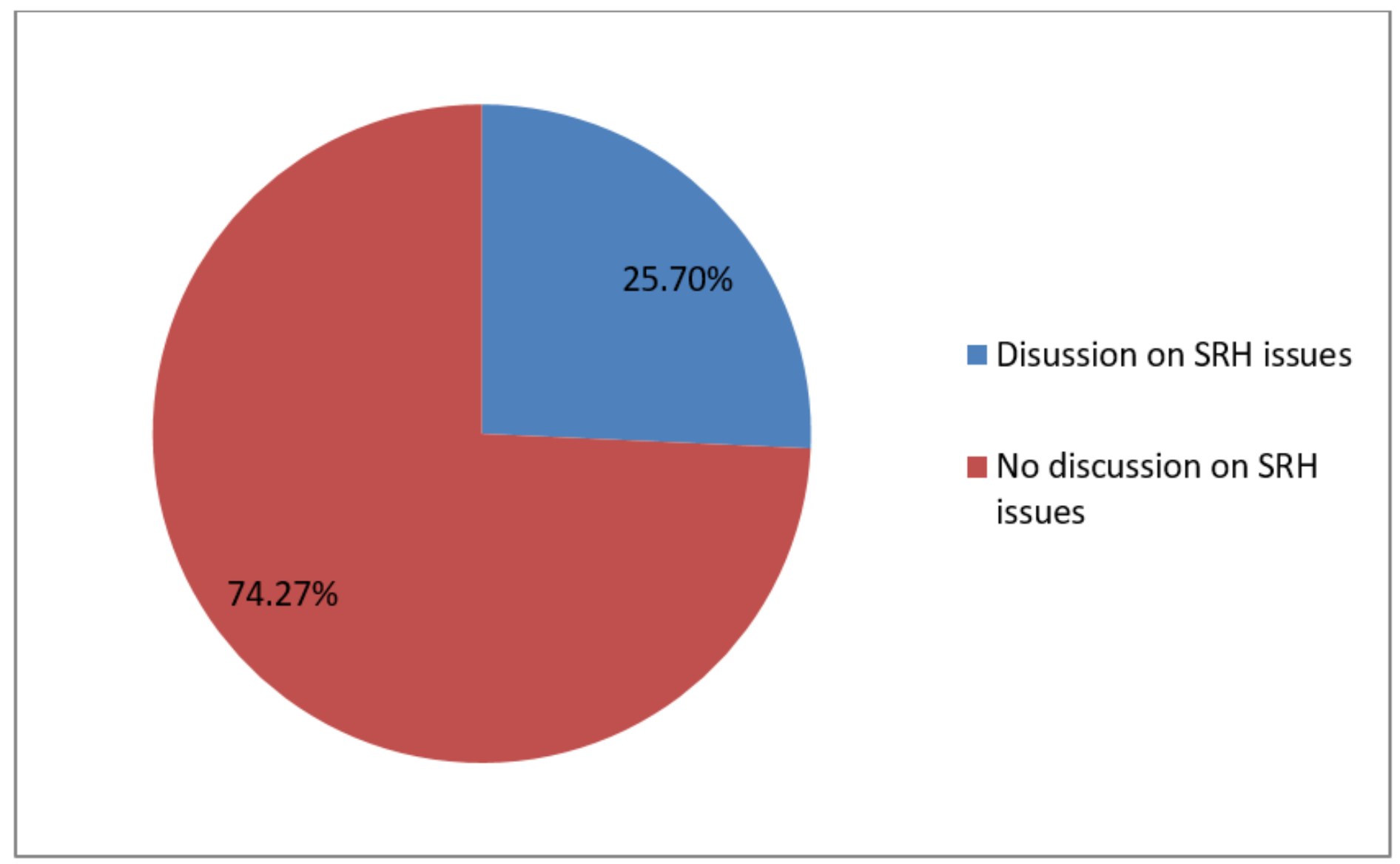

Figure 2

Distribution of parent-adolescent discussion on SRH issues in Sawla town, Southern Ethiopia 2020 $(n=653)$ 